\title{
FUNDAMENTOS TEÓRICOS QUE ENVOLVEM A CONCEPÇÃO DE CONCEITOS CIENTÍFICOS NA CONSTRUÇÃO DO CONHECIMENTO DAS CIÊNCIAS NATURAIS
}

\author{
Theoretical foundations which involve the conception of \\ scientific concepts in the construction of knowledge in the \\ natural sciences
}

Francimar Martins Teixeira ${ }^{1}$

\section{RESUMO}

Analisamos entendimentos do que são conceitos científicos e as situações didáticas para o ensino e aprendizagem que deles depreendem-se. Em um primeiro entendimento, tais conceitos são vistos como rótulos que nomeiam conjuntos de atributos ou propriedades perceptíveis, dados objetivos e fatos encontrados no mundo. Em contraposição, há o entendimento de que conceitos científicos são substantivos que compactuam uma rede flexível de conhecimentos articulados e concatenados. Em relação aos processos de ensino e aprendizagem, identificamos que no primeiro entendimento há ênfase no aprendizado de definições e na execução de experimentos que evidenciem as propriedades que o conceito define, enquanto no segundo entendimento o foco é a capacidade de articulação de informações em função do contexto em que ele é empregado.

Palavras-chave: Conceitos Científicos, Definições, Rede de Conhecimentos.

\section{ABSTRACT}

I have analysed understandings of what scientific concepts are and the didactic situations for the learning and teaching which can be inferred from them. In one of the interpretations those concepts are seen as labels which name sets of qualities or perceptible properties: objective data, facts found in the world around us. Conversely, there is the understanding that scientific concepts are nouns which share a flexible network of well founded and logical knowledge. Regarding the teaching and learning processes, I have identified that in the former interpretation there is an emphasis on the learning of definitions and the carrying out of experiments that highlight those properties which the concept defines; whereas, in the latter understanding, the focus is on the capacity to make sense of the information bearing in mind the context in which it is used.

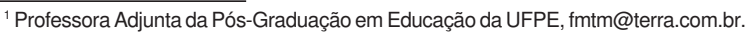


Key words: scientific concepts, definitions, network of knowledge INTRODUÇÃO

Os conceitos científicos são centrais no ensino de Ciências Naturais. Com eles são expressas explicações, descritas propriedades e feitas previsões para os fenômenos. Tal centralidade está reconhecida nos Parâmetros Curriculares Nacionais, quando estabelecem como uma das metas de ensino nessa área o saber utilizar conceitos científicos (BRASIL, 2000). Defendemos que, se temos uma teorização sólida do que são os conceitos científicos, teremos mais subsídios para elaborar atividades que promovam o seu aprendizado.

Analisando o entendimento do que são conceitos científicos e como ocorre o seu aprendizado, observamos que não há um consenso entre os estudiosos sobre esse assunto. As diferentes abordagens sobre como podem ser desenvolvidas as atividades de ensino para o aprendizado de conceitos científicos vêm sendo divulgadas, influenciando o trabalho dos professores, até mesmo quando eles nem têm consciência de como entendem o que sejam tais conceitos, ou qual é a concepção sobre o que são conceitos, na qual as atividades desenvolvidas se embasam. No presente artigo discutimos o que são conceitos científicos segundo diferentes perspectivas teóricas e as suas implicações para o processo de ensino-aprendizagem.

\section{Conceitos entendidos como rótulos}

Um dos significados dado a conceito é que se trata de uma palavra ou símbolo que rotula objetos, eventos, situações ou propriedades que partilham de atributos em comum (AUSUBEL et al., 1980; NOVAK, 1988.). Por exemplo, ave é a palavra que nomeia todos os animais que têm asas, bico e penas. Portanto, o termo ave expressa um conceito porque, ao empregá-lo, estamos rotulando através de uma única palavra, as regularidades e os atributos que todos os animais classificados como tal apresentam. Ao usarmos o símbolo $\mathrm{H}_{2} \mathrm{O}$, estamos empregando o conceito água, porque é esse o termo que nomeia a substância composta na proporção de dois átomos de hidrogênio para um de oxigênio. Em resumo, ave e $\mathrm{H}_{2} \mathrm{O}$ são conceitos por serem rótulos para informações referentes a um conjunto de atributos específicos.

Seguindo essa visão, o conceito assume a conotação de definição: um único termo agrega diversas informações precisas uma vez que anuncia um conjunto de atributos ou propriedades que um fato ou objeto tem e delimita o que pode ou não ser nomeado por aquele termo (TEIXEIRA, 2004). Desse modo, se o conjunto de atributos que o conceito rotula não é encontrado em um determinado fato ou objeto, então o conceito não pode ser aplicado. Por exemplo, ao falarmos em ave estamos nomeando uma categoria de animais com atributos específicos; no caso, animais que têm bico, penas e asas. Animais que não apresentam esses atributos em conjunto não são conceituados como ave.

Decorrente da lógica de conceitos como rótulos dados aos agrupamentos de informações, podemos caracterizá-los como sendo (ROCHA, 2002):

1. generalizações a partir de casos localizáveis empiricamente: cada conceito resulta da abstração de informações sobre objetos ou eventos perceptíveis. Ele é a construção de generalidade a partir de casos específicos, empiricamente localizáveis;

2. representações mentais de categorias localizáveis no mundo empírico. O conceito ave, por exemplo, não tem existência empírica concreta; ele representa a abstração de informações sobre várias espécies animais que apresentam, em comum, algumas semelhanças.

3. um conjunto de informações fixas adquiridas pelos indivíduos. Isto é, não há 
variação no significado do conceito. Uma vez que ele é aprendido, ele será utilizado pelo indivíduo, ao longo da sua existência, sem alteração do seu significado. No caso do conceito ave, ainda que novas informações a respeito das mesmas sejam produzidas ou que o indivíduo empregue o conceito ave em diferentes contextos, a definição do que é ave permanece inalterada: trata-se de animal com penas, bico e asas;

4. um estoque de informações memorizadas. Quanto mais informações forem acumuladas, maior será o conhecimento. Assim, tanto a aprendizagem quanto o desenvolvimento cognitivo são conseqüências da memorização: o indivíduo aprende o que ele memoriza e todas as funções que o fazem alcançar estágios intelectuais mais elaborados decorrem do uso que ele faz do que memorizou. Ambos, aprendizagem e desenvolvimento cognitivo confundem-se com a memorização e o uso das informações.

5. Em conformidade com o entendimento de que os conceitos são rótulos dados aos agrupamentos de informações, tem-se a descrição de que os mesmos são adquiridos através das associações percepto-sensitivas, por meio da identificação dos atributos salientes - as características externas dos objetos e eventos -, julgamento das similaridades e diferenças desses atributos salientes com os dados registrados na memória e a associação de um termo para nomear o conjunto de atributos. Mais exatamente, identifica-se, no processo de aquisição, três momentos:

$1^{\circ}$ - O indivíduo tem alguma experiência com certos exemplares do conceito. Voltando ao conceito de ave, é possível que essa experiência tenha sido a de ver alguns tipos de ave na TV ou no zoológico ou, ainda, em gravuras em livros. $2^{\circ}$ - Há a identificação de atributos comuns dentre a multiplicidade de características que o exemplar apresenta. Vejamos uma ilustração: ao ver-se um pato e um pardal, identifica-se que ambos têm penas, bico e asas, apesar de eles apresentarem diferenças na cor e no formato.

$3^{\circ}$ - É estabelecida uma representação mental desse grupo de atributos, ou propriedades comuns, e atribuído um nome a ele. Em outras palavras, os indivíduos memorizam os traços identificados como sendo comuns aos exemplares e aprendem um nome para esse conjunto de traços. No caso da nossa ilustração, todos os animais que apresentam penas, bico e asas passam a ser chamados de ave (TEIXEIRA, 2004).

Até aqui analisamos conceitos em geral. Voltando, exclusivamente, aos conceitos científicos, encontramos entre os defensores da idéia dos primeiros como rótulos para conjuntos de atributos ou propriedades perceptíveis. A defesa do segundo grupo de conceitos também apresenta as mesmas características: ambos são considerados como termos que nomeiam dados objetivos, fatos encontrados no mundo, alegandose que os referentes dos conceitos estão no mundo real; não são idéias na mente do cientista. São descobertas ou invenções apenas no sentido de ter-se desenvolvido um ambiente verbal no qual propriedades obscuras da natureza são postas sob controle do comportamento humano (SKINNER, 1993, p. 94).

Em outras palavras, o cientista constata regularidades no mundo empírico, faz o registro do que verificou, enumerando todas as propriedades, descrevendo em que circunstâncias elas são observadas e lhes dá nomes. Portanto, a diferença entre conceitos não científicos e conceitos científicos é que o segundo grupo foi produzido através do registro do que foi observado e da descrição precisa das circunstâncias em que foram observadas.

Nesse argumento, o cientista é visto como alguém que descreve objetivamente as coisas tais como elas aparecem, identificando aspectos da natureza que são fixos, imutáveis e verdadeiros para todos os tempos e lugares e, por isso, podem ser descritos 
como leis (CHALMERS, 1993; OLIVEIRA, 1999). A ciência é concebida como "um tipo de consciência grupal" (SKINNER, 1993, p. 125) em que "aquilo que é comunicado entre os cientistas são enunciados de fatos, regras e leis" (SKINNER, 1993, p. 125).

Como o resultado da atividade do cientista é a de descrever fatos, identificar regularidades e apontar as regras das relações de causa e efeito, revelando as leis que regem esses fatos, tem-se uma produção linear, sem conflitos, de um corpo de conhecimento acumulativo, isto é, as produções atuais dos cientistas somam-se a outros conhecimentos já anunciados anteriormente, aumentando as explicações para os fenômenos, sem contradições com o que foi produzido anteriormente (CHALMERS, 1993).

Em decorrência da objetividade da produção do conhecimento científico, os conceitos que expressam tal conhecimento são considerados como sendo enunciados que tornam "possível a outras pessoas responderem efetivamente sem terem sido pessoalmente expostas a esse mundo" (SKINNER, 1993, p. 125). Pressupõe-se que, se algum dia forem expostas ao conjunto de atributos ou propriedades que o conceito rotula, ou for dito quer seja sobre as leis que regem os fatos ou sobre os atributos ou propriedades que um conceito rotula, terão condições ou de constatar ou de entender tudo o que o cientista já havia descrito.

No Brasil, desde 1838, visando-se ao ensino dos conceitos científicos no âmbito escolar, têm sido elaborados materiais didáticos, como apostilas, compêndios, livros didáticos, cadernos de trabalho, caixas com materiais para experimentos e manual de instrução para a execução dos mesmos (BARRA \& LORENZ, 1986).

Por vezes, esses materiais preconizam a vivência de experimentos para que se aprenda como ocorre o processo de investigação, ao mesmo tempo em que se percebe tudo aquilo que o cientista constatou quando estava sistematizando o conhecimento (ARRUDA e LABURÚ, 1998). Apontamos o plantio de feijão, atividade comum nas séries iniciais das escolas brasileiras, como um desses 'experimentos'. As crianças plantam o feijão, regam-no diariamente, acompanham o seu desenvolvimento e, posteriormente, constatam 'tal como os cientistas já haviam concluído', que as plantas para sobreviverem precisam de água e luz.

Muito freqüentemente os recursos didáticos para o ensino de ciências trazem pequenos textos com definições e informações simplificadas (CICILLINI, 2002) e, às vezes, ilustrações, implicitamente assumindo que, se o conhecimento científico é objetivo, provado e confiável, então, memorizando as definições e sendo informados das propriedades e leis que regem os fatos, haverá o entendimento do que dizem os cientistas (SILVEIRA e CICILLINI, 2002). Por exemplo: o processo de digestão seria aprendido memorizando-se a definição do que é digestão, o nome e a função dos órgãos. Gravuras que mostram o sistema digestivo como uma grande fábrica, onde cada órgão é um setor dessa fábrica, facilitariam o entendimento e o aprendizado do conceito de digestão.

Embora existam diferenças em relação às atividades propostas nos materiais didáticos, embasados na concepção de conceitos científicos como termos que rotulam conjuntos de atributos ou propriedades, eles apresentam, em comum, primeiramente, o fato de focalizarem os fenômenos exclusivamente em si, sob a perspectiva natural, isto é, a descrição de fatos e propriedades observadas na natureza; em segundo lugar, assumem que os conhecimentos produzidos acerca de tais fenômenos são, ao longo da história, inalterados (COSTA, 2000). Não são feitas relações do que é estudado com a vida do aprendiz, dos aspectos culturais relacionados aos fenômenos naturais, às implicações sociais que tais fenômenos acarretam, a história do conceito em questão, incluindo a explicitação das transformações pelas quais ele passou ao longo dos tempos.

Assim, em relação ao conceito água, são trabalhadas a fórmula, características e propriedades, sem nenhuma referência sobre a história da fórmula, da identificação das características e propriedades não visíveis a olho nu (MORTIMER, 1996), da 
correlação positiva entre a distribuição da água e o poder aquisitivo da população brasileira nas grandes cidades, ou sobre guerras entre nações pela posse de territórios com água em abundância. Aprende-se a classificar um animal como ave, peixe ou réptil, sem indicadores do porquê ou para quê classificamos animais. Além disso, lida-se com os critérios e regras para classificação como se esses sempre tivessem sido os mesmos. Ensina-se sobre os sistemas do corpo humano, dissociando-o das condições de vida dos indivíduos.

Os indivíduos que entendem conceitos como rótulos tratam o processo de aprendizagem dos mesmos como sendo linear e regular: a um conhecimento vão ser, continuamente, somados outros conhecimentos, sem conflitos. Desse modo, é possível estruturar um sistema escolar seriado, com uma lista pré-definida de conteúdos a serem trabalhados. Esses se completam e são ampliados a cada segmento da seriação. Infelizmente, foi constatado que, no Brasil, houve uma simplificação dos conteúdos e montagem de situações, quer sejam de experimentos quer sejam de textos, chegandose a um nível de informação em que são excluídos aspectos essenciais do conhecimento, tornando-o incompreensível para o aluno (CICILLINI, 2002) e, adicionalmente, criou-se à imagem de que a ciência é um refinamento do senso comum (COSTA, 2000).

Nesse contexto, as atividades experimentais são para produzir resultados já esperados, que comprovam um conhecimento já estabelecido (COSTA, 2000). Assim, o ensino de conceitos científicos caracteriza-se como sendo um processo sem inquietações, no qual a meta é memorizar o que já está estabelecido: a informação 'correta' e/ou 'o método' pelo qual os conceitos científicos são gerados.

\section{Críticas ao Entendimento dos Conceitos como rótulos:}

Considerar conceitos científicos como rótulos nos coloca diante de um impasse, ao nos depararmos com fatos ou objetos que, para serem entendidos, requerem mais que a mera identificação de atributos. Por exemplo: não é possível entender o papel do coração humano apenas identificando as suas propriedades. Também não faz sentido identificar que características esse órgão tem em comum com outros, uma vez que ele tem peculiaridades anatômicas e funcionais que o tornam distinto dos demais. Em alguns outros conceitos é difícil encontrarmos contrapartida empírica, de modo a termos mais de um exemplar para abstrairmos propriedades em comum, como é o caso da luz.

Em alternativa à noção de conceitos como rótulos, tem sido proposta a noção de conceitos como sendo uma rede flexível de conhecimentos articulados, um conjunto de informações concatenadas que permitem descrever, prever e explicar as causas dos fenômenos. Cada conceito seria constituído por uma série de outros conceitos. Por exemplo: conceituar o processo de digestão como a atividade de quebra do alimento requer o entendimento de que essa quebra acontece devido a processos mecânicos e químicos. Por sua vez, é preciso entender o que são os processos mecânicos e o que são os processos químicos, onde eles acontecem, em que seqüência acontecem e que alterações eles promovem no alimento ingerido.

Seguindo essa visão, o "conceito" digestão, assim como qualquer um outro conceito, está situado dentro de uma vasta rede de conhecimentos, na qual, quando ele é posto em evidência, torna-se o centro dessa. Para de fato se compreender o conceito de digestão tal como ele é amplamente aceito nos meios acadêmicos atualmente, é preciso conceber o organismo como um sistema: cada parte tem função distinta, embora correlacionada, de modo a se completarem formando um conjunto.

Portanto, digestão é uma parte desse conjunto; respiração e circulação, uma outra parte. Ao buscarmos entender o que é digestão, direcionamos a rede conceitual no sentido de esclarecer toda a estrutura e funcionamento do aparelho digestivo. Assim, colocamos esse aparelho em evidência, ou, como foi dito anteriormente, o colocamos como o centro da rede conceitual. $O$ entendimento do que é digestão será ainda mais 


\section{ensaio}

vol $8 \cdot n^{\circ} 2 \cdot$ dez. 2006

completo se outros aspectos - que são outros pontos dessa rede - forem articulados. Nessa perspectiva, os conceitos constituem explicações com as quais pensamos e sobre as quais podemos pensar: Eles são, concomitantemente, os elementos com os quais articulamos informações e os próprios conteúdos sobre os quais pensamos.

Conceber conceitos como a articulação de conhecimentos caracteriza-os como algo dinâmico, pois, dependendo do que for articulado, teremos variações no produto final. Um mesmo indivíduo tanto pode dar diferentes direções para a sua rede conceitual, diversificando o conteúdo do conceito, quanto variar a quantidade de informações com as quais ele lida. Portanto, estamos admitindo a possibilidade de um mesmo indivíduo ativar informações diferentes, de modo a apresentar, como produto, conceitos diferenciados para um mesmo fato ou fenômeno.

Mortimer (2000, p. 77-78) ilustra essa possibilidade analisando o conceito de massa, que tanto pode ser considerada, por um mesmo indivíduo, como aquilo que é pesado, o que pode ser medido pela balança, quanto o quociente da força pela aceleração, como, também, ser analisada em relação ao deslocamento do objeto. Um físico, que embora tenha o complexo entendimento que massa não é um sistema de unidade absoluto, mas está relacionado à velocidade, pode, no seu cotidiano, falar em 'massa de ar frio que se aproxima' ou de uma 'massa de detalhes a serem trabalhados no projeto', atribuindo 'massa' somente a coisas grandes e pesadas, aquilo que é apreciado pela visão.

Um outro exemplo ilustrativo de que a flexibilidade de ativação da rede conceitual pode gerar conceitos diferenciados para um mesmo fato ou fenômeno, por parte de um mesmo indivíduo, é apresentado por Carraher, Carraher e Schiliemann (1988), quando mencionam o conceito de inverno empregado em relação a uma estação do ano, no nordeste e no sul do Brasil. Apesar de lidar com o conceito de inverno em ambas as situações, o indivíduo não está referindo-se, exatamente, a mesma coisa: enquanto na primeira situação fala-se do período chuvoso e com calor, na segunda refere-se à época do ano em que faz frio.

Conseqüentemente, o conceito entendido como uma rede de conhecimentos não é algo fixo, que o indivíduo tem ou não tem, limitando, de modo claro, as propriedades que ele abarca, identificando com precisão os atributos relacionados ao mesmo e, invariavelmente, empregado com um significado único.

Vergnaud $(1982,1986)$ apresentou argumentos teóricos que esclarecem a variação do significado dos conceitos ao sugerir que eles envolvem três aspectos indissociáveis: situações, invariantes e símbolos. As situações são os eventos que dão significado ao conceito - o contexto em que esse é utilizado. Os invariantes são as propriedades, os atributos que o definem; os símbolos dizem respeito às formas de representação. A variação em um desses aspectos resulta em um conceito diferente, ainda que eles tenham em comum dois outros aspectos. Vejamos uma ilustração do que diz Vergnaud: entrevistando crianças de 4, 6, 8 e 10 anos sobre por que comemos, elas responderam que é para ficar forte, com saúde, para não morrer (TEIXEIRA, 1995). Se nos apoiássemos na concepção de conceitos como definições, rótulos a propriedades, poderíamos defender que elas têm o mesmo conceito. Contudo, os invariantes utilizados para responder a situação a que foram expostas, nomeadamente à indagação do por quê comemos, diferiam profundamente entre as crianças. Eis dois exemplos:

Exemplo 1:

(E) - Como é que a comida faz dentro da gente que deixa a gente com força?

(C) - Porque nosso estômago fica muito pesado, assim, com muita comida (L. Alfabetização) (TEIXEIRA, 1995, p.40).

Exemplo 2: 
(E) - E como é que a alimentação deixa a pessoa com mais saúde?

(C) - Porque é forte, aí se comer muito aí a gente fica com saúde. (...) Tem as comidas tem aquele negócio fraquinho, né? Aí tem as comidas fracas, aí pode dar quando tá gripado.

(E)- Quais são as comidas fracas?

(C)- É macarrão

(E)- E por que elas podem dar quando tá com gripe?

(C)- Porque elas são fracas, aí dá.

(E)- E por que a forte não dá quando tá com gripe?

(C)- Porque é muito forte, aí se dá ela continua.

(E)- Ah, é? Se eu der uma comida forte a uma pessoa que tá gripada aí a gripe vai continuar? Se eu der uma comida fraca a gripe vai passar?

(C)- Vai passando devagarinho (M. segunda série) (TEIXEIRA, 1995, p.40).

Enquanto para L. é o peso da comida no estômago que nos faz ficar fortes, para M são as características da comida que são relevantes. No caso, são elas que irão fortalecer ou enfraquecer a gripe. Se for ingerida comida forte, a gripe ficará forte e 0 indivíduo continuará gripado; se for ingerida comida fraca, a gripe ficará fraca e vai passar. No exemplo 1, o de L., a força advém da quantidade de comida, e no exemplo 2, dado por M., a força está relacionada às características da comida, que estão classificadas em dois grupos: um grupo de comidas fortes e um grupo de comidas fracas. Quem come comida forte, fica forte e quem come algo fraco, fica fraco. Considerando o argumento de Vergnaud $(1982,1986)$, diante de uma mesma situação, apesar de ambas as crianças indicarem que a comida nos faz ficar fortes, elas estão lidando com propriedades diferentes; conseqüentemente, estão apresentando conceitos distintos. É oportuno destacar que, ainda com base nesse argumento (VERGNAUD, 1982, 1986), as pessoas podem estar usando as mesmas palavras sem, necessariamente, estarem tratando do mesmo conceito.

Mortimer (2000), em consonância com a proposição de Vergnaud (1982, 1986), também identificou que um mesmo indivíduo pode dispor de diferentes conceitos para o mesmo fato ou propriedade. Tais conceitos seriam ativados por diferentes contextos, dado que as pessoas possuem diferentes formas de ver e representar a realidade a sua volta. Ao recorrer a um conceito, está-se focalizando um aspecto dessa representação da realidade, não esgotando todas as possibilidades de quais são os conceitos que 0 indivíduo tem para a realidade que está em questão. Por isso, em vez de falar de conceito, o autor refere-se a perfil conceitual, isto é, os conceitos estariam organizados em categorias, compondo uma escala graduada, que vai desde as noções do senso comum, usadas no cotidiano, até as mais complexas e racionais - conforme foi ilustrado acima, em relação ao conceito de massa. Cada categoria constitui uma divisão diferente do perfil e está relacionada a uma perspectiva filosófica específica, baseada em compromissos epistemológicos distintos. Cada parte do perfil pode ser relacionada, portanto, com uma forma de pensar e com um certo domínio ou contexto a que essa forma se aplica (MORTIMER, 2000, p. 73). Por exemplo: uma pessoa com formação científica poderia rir da ingenuidade do pensamento infantil, capaz de inventar a entidade frio em contrapartida ao calor, e de distinguir duas formas de "energia" que podem fluir de um corpo ao outro - o calor e o frio (ERICKSON, 1985). No entanto, no seu cotidiano, essa pessoa continuará a usar esses conceitos de uma forma muito natural. Mesmo porque soaria pedante alguém afirmar que "vestiu uma blusa de lã porque ela é um bom isolante térmico, impedindo que o corpo ceda calor para o ambiente". Ora, nós vestimos lã porque ela é quente e nós estamos com frio. Não há aí nenhum vestígio de concepções ingênuas, mas o uso da palavra calor num sentido de senso comum que a nossa cultura consagrou (MORTIMER, 2000, p. 60).

Propõe-se, assim, que o indivíduo dispõe a sua rede conceitual em função do 
contexto específico em que ela está sendo usada. O que é disposto em um contexto pode ser distinto do que será ativado para atender às demandas de uma outra situação ou de situação similar, ativada em momento diferente. Portanto, conceitos de senso comum continuam a existir e a serem usados, até mesmo por aqueles que se apropriaram de conhecimentos científicos de ponta. Concomitantemente, um mesmo indivíduo pode apresentar conceitos científicos diferenciados para um mesmo fato ou fenômeno, dado que ele pode recorrer a diferentes escolas de pensamento, existentes no seu perfil conceitual. Por exemplo: o conceito de átomo enquanto objeto quântico difere do conceito de átomo analisado segundo a perspectiva clássica. Mesmo ciente dessas diferenças, um químico, com sólida cultura quântica, pode empregar a visão daltoniana de átomo enquanto indestrutível e indivisível (MORTIMER, 2000).

No bojo dessa discussão, identifica-se que os conceitos científicos tanto não são considerados como sendo "enunciados de fatos, regras e leis" (SKINNER, 1993, p. 125), quanto não são tidos como a expressão elaborada daquilo que é encontrado no conhecimento de senso-comum, por ter sido produzido através do registro do que foi observado e da descrição precisa das circunstâncias em que foram observadas. Em vez disso, entende-se que o conceito científico distingue-se do conceito de senso comum por ser um enunciado que expressa informações de um modelo de explicação causal que, além de possibilitar descrever o fenômeno, estabelecer implicações da causa e efeito, esclarece, também, os porquês e o como do fenômeno.

Portanto, seguindo essa lógica, o conceito científico não expressa informações sobre o real, o imediatamente observável. Trata-se da expressão de um entendimento circunscrito a um modelo, que lida com informações abstratas, construídas por uma comunidade científica e atribuídas aos objetos, de modo a gerar uma mesma explicação causal para interpretar fenômenos que, do ponto de vista empírico, isto é, da mera observação das propriedades visíveis, podem até ser distintos. Por exemplo, os átomos não existiam nos objetos, foram construídos por uma comunidade científica e atribuídos aos objetos. Do ponto de vista empírico, um sólido aparentemente nada tem a ver com um líquido, mas, do ponto de vista do atomismo, são todos constituídos por partículas, e as diferenças nas propriedades dependem da diferença na interação entre essas partículas (MORTIMER, 2000, p. 123-124).

Nessas considerações está subjacente o entendimento de que o conhecimento científico é uma ruptura com o conhecimento de senso comum. Enquanto o primeiro é informação construída a respeito de uma realidade, um conhecimento sobre algo que não tem realidade material, uma concretude física, o segundo é uma generalização empírica, extraída do observável que não apresenta informações para explicar o porquê dos fenômenos (BACHELARD, 1984).

Destacamos que ruptura implica tornar-se distinto, o que não quer dizer superioridade de um conhecimento em relação ao outro ou contradição dos saberes gerados. Por exemplo: há indicadores sugestivos de que os índios brasileiros eram cientes de que a mandioca crua é tóxica, embora não haja registro de que eles sabiam a causa da toxidade. Por outro lado, os cientistas identificaram que na mandioca encontrase veneno do grupo dos cianogênicos, corroborando, assim, o saber de senso comum entre os índios (BIZZO, 1998), ao tempo em que se distingue dele por apresentar a informação de que apenas observando a mandioca, ou os efeitos por ela causados após ser ingerida, não poderia ser elaborada.

Martins (2001) aponta que a produção do conhecimento científico envolve a problematização, isto é, a capacidade de observar um fenômeno e pensar neles como necessitando de explicação. "Por exemplo, a maior parte das pessoas reconhece que os metais brilham e não pensam nisso como algo que possa ser explicado mas sim como algo que caracteriza os metais e, portanto, não necessita ser problematizado" (MARTINS, 2001, p. 143). Ambos, problematização e explicação dos porquês e do como 
de um fenômeno, não são necessários no conhecimento de senso comum.

Quando se comunica um conhecimento científico, todos os conceitos através dos quais tal conhecimento é expresso remetem a problemas e implicam explicações. Por isso, o conceito científico é considerado um código de compactação, dado que um único termo junta informações e agrega significados (BIZZO, 1998). Para alguns pesquisadores, na comunicação das idéias cientificas são utilizados metáforas gramaticais, em que um processo torna-se um substantivo (MARTINS, OGBORN \& KRESS, 1999). Vejamos um exemplo: o substantivo refração refere-se ao processo de "mudança de direção de propagação da luz quando esta entra num meio material transparente como ar ou água" (MARTINS, OGBORN \& KRESS, 1999, p. 32). Desse modo, o substantivo refração compacta informações e dispensa a descrição sobre um processo.

Todas essas considerações em torno dos conceitos científicos, desde caracterizálos como substantivos, que compactuam uma rede de conhecimentos explicativos dos porquês dos fenômenos até as evidências de que estão organizados em perfis, levamnos a tecer algumas implicações para as questões cotidianas de encaminhamentos do processo formal de ensino e aprendizagem dos mesmos.

Ao serem elaboradas estratégias didáticas, é preciso considerar que, se 0 aprendizado de um novo conhecimento científico não requer o abandono de outros conhecimentos, quer seja de uma outra teoria científica ou de saberes de senso comum na cultura do indivíduo, então, conforme sugeriu Mortimer (2000), ao invés de se pensar que o aprendizado de conhecimento científico substituirá o conhecimento prévio, passase a argumentar que o indivíduo está sendo introduzido a uma nova cultura, nomeadamente a um outro modelo explicativo, outra linguagem e história. Como parte do aprendizado estaria a tomada de consciência de que as diferentes formas de pensar devem ser adequadas ao contexto em que elas são empregadas.

Concretamente, é preciso trazer para a sala de aula situações que possibilitem ao aluno expor o que ele pensa e criar condições para que ele aprenda outros argumentos e formas de analisar o fenômeno, convencendo-o de que esses são mais contundentes e apropriados em alguns contextos que os que ele propunha anteriormente, mas, em outras situações, tais argumentos soariam como pedantes e desnecessários.

Desse modo, o conhecimento científico assume o caráter que de fato ele tem: trata-se de uma produção humana, marcada pelo contexto histórico do momento da sua produção, o que inclui desde os instrumentos até os interesses políticos e econômicos que viabilizaram a sua produção. Deixa-se de lado a visão idealizada de conhecimento científico como explicações eternas, inalteráveis. A História da ciência, passa a ser fonte relevante para o planejamento das atividades de ensino, constituindose como evidência de que os conhecimentos científicos, longe de serem cópia do real, do observável, são explicações sobre o que está subjacente ao observável. São essas explicações o principal alvo a ser trabalhado em sala de aula.

Deslocando-se da perspectiva de que os conceitos científicos são definições, rótulos para o que se vê, e passando-se a considerá-los como redes de conhecimentos que em conjunto explicam algo, o professor precisa investigar se os conceitos empregados pelos alunos estão incluindo os invariantes e símbolos vinculados pela explicação causal que ele substantiva, ou se o aluno apenas memorizou termos que ele emprega sem clareza da teoria na qual os conceitos estão emersos. Mas, acima de tudo, é interessante ressaltar que a capacidade de articular a rede de conhecimentos precisa ser estimulada, trabalhada, com toda ênfase. Diálogo, argumentos e apresentação de evidências deveriam ser práticas corriqueiras do cotidiano escolar. Adicionalmente, músicas, filmes, literatura, matérias de jornais, enfim, outras formas de produção que não a científica podem ser fontes de informação e recursos preciosos para o exercício da criatividade e do pensar criticamente (atividades imprescindíveis 


\section{ensaio}

vol $8 \cdot \mathrm{n}^{\circ} 2 \cdot$ dez. 2006

para que sejam estabelecidas as articulações entre conhecimentos).

Reconhecemos que traduzir para uma prática pedagógica tal entendimento do que são conceitos científicos é um grande desafio. Instaurar debates, trocar experiências socializando acertos, desacertos, incertezas, conquistas e frustrações são atividades que podem nos ajudar a construir coletivamente essa tradução.

\section{REFERÊNCIAS BIBLIOGRÁFICAS}

ARRUDA, Sérgio de M. e LABURÚ, Carlos. E. Considerações sobre a função do experimento no ensino de ciências. In: NARDI, Roberto. (Org.). Questões atuais no ensino de ciências. São Paulo: Escrituras, 1998. p. 53-60.

AUSUBEL, David P.; NOVAK, Joseph D.; e HANESIAN, Helen. Psicologia Educacional. Rio de Janeiro: Interamericana, 1980. p. 625.

BACHELARD, Gaston. A filosofia do não. São Paulo: Abril Cultural, 1984. p. 1-87.

BARRA, Vilma M.; LORENZ, Karl M. Produção de materiais didáticos de ciências no Brasil, período 1950 a 1980. In: Ciência e Cultura, v. 38, n¹2, p.1970-1983, dez. 1986.

BIZZO, Nelio. Ciências: fácil ou difícil? São Paulo: Ática, 1998. 144p.

BRASIL, MEC/SEF. Parâmetros Curriculares Nacionais - Ciências Naturais. $1^{\mathrm{a}}$ a $4^{\mathrm{a}}$ séries, 2000.

CARRAHER, Terezinha; CARRAHER, David \& SCHLIEMANN, Analúcia. Na vida dez, na escola zero. São Paulo: Cortez, 1988. 182 p.

CHALMERS, Alan.F. O que é ciência afinal? São Paulo: Brasiliense, 1993. 225p.

CICILLINI, Graça. Aparecida. A prática dos professores de Biologia e a simplificação de conteúdos. In: Ensino em RE-Vista. Uberlândia, v. 9, n 1, p. 41-58, abril, 2002.

COSTA, Regina Calderipe. construção do conhecimento científico segundo algumas contribuições da epistemologia de Bachelard. In: MORAES, Roque (Org.). Construtivismo e ensino de ciências: reflexões epistemológicas e metodológicas. Porto Alegre: EDIPUCRS, 2000. p. 69-102.

MARTINS, Isabel. Explicações, representações visuais e retórica na sala de aula de Ciências. In: MORTIMER, Eduardo Fleury. \& SMOLKA, Ana Luiza B. (Orgs.). Linguagem, cultura e cognição. Reflexões para o ensino e a sala de aula. Belo Horizonte: Autêntica, 2001. p.139-150.

MARTINS, Isabel; OGBORN, John \& KRESS, Gunter. Explicando uma explicação. Ensaio - Pesquisa em Educação em Ciências, Belo Horizonte, v. 1, n. 1, p. 29-46. 1999.

MORTIMER, Eduardo Fleury. H2O=Água? O Significado das formulas químicas. Química Nova na Escola, n 3, p.19-21, maio. 1996.

Linguagem e formação de conceitos no ensino de Ciências. Belo Horizonte: Universitária UFMG, 2000. 383p. 


\section{ensaio}

$\operatorname{vol} 8 \cdot \mathrm{n}^{\circ} 2 \cdot$ dez. 2006

NOVAK, Joseph. D. Uma teoria de educação. São Paulo: Pioneira, 1988.

OLIVEIRA, Marcos Barbosa. de. A Tradição Roschiana. In: OLIVEIRA, M.arcos Barbosa de \& OLIVEIRA, Marta Kohl de. Investigações cognitivas. Conceitos, linguagem e cultura. Porto Alegre: Artes Médicas Sul, 1999. 160p.

ROCHA FALCÃO, Jorge Tarcísio da. Psicologia e Educação Matemática. Educação em Revista, Belo Horizonte, v. 36, p. 205-221, dez. 2002.

S.ILVEIRA, Hélder Eterno da. \& CICILLINI, Graça. Aparecida. O conhecimento químico em apostilas do Ensino Fundamental. Ensino em RE-Vista. Uberlândia, v. 9, n. 1, p.135156, abr. 2002.

SKINNER, Burrhus F. Sobre o Behaviorismo. São Paulo: Cultrix, 1993. 216p.

TEIXEIRA, Francimar M. Concepções das crianças sobre alimentação, estrutura e funcionamento do aparelho digestivo. Recife; 1995. 208p. Dissertação (Mestrado em Psicologia Cognitiva) - Centro de Filosofia e Ciências Humanas da Universidade Federal de Pernambuco.

Teorias sobre a origem do conhecimento biológico na infância: avanços, limites e implicações. Educação em Revista. Belo Horizonte, n 39, p. 61-78. jul. 2004

VERGNAUD, Gerard. Psicologia cognitiva e do desenvolvimento e pesquisa em educação matemática: Algumas questões teóricas e metodológicas. Texto baseado na apresentação para o Grupo Canadense de Estudos em Educação Matemática na Queen's University, Kingston. Jun. 1982. Trad.: Jeanette Verônica Weiss. Revisão: Sylvia Judity Hamburger Mardel, 1987.

Psicologia do desenvolvimento cognitivo e didática das matemáticas. Um exemplo: as estruturas aditivas. Análise Psicológica, v.1, p.74-90, 1986.

Data de recebimento: 28/04/2006

Data de aprovação: 12/05/2006 